\title{
Demand Side Management and its Possibilities in Jordan
}

\author{
Nabeel Tawalbeh',Hanan Mohammad Abusamaha2* , Ahmed Al-Salaymeh² \\ 1 Electrical Engineering Department, The University of Jordan, Amman, Jordan \\ 2 Mechanical Engineering Department, The University of Jordan, Amman, Jordan \\ * Corresponding author e-mail: hanansamaha83@gmail.com
}

\begin{abstract}
The increase in energy consumption and energy bills in Jordan have been escalating rapidly, which requires a special concern as a large percent of the energy is imported. The need for the reducing peak demand of the distribution network is essential to decrease the overall electricity generation cost. This study was aimed at presenting a model for a home that manages its energy consumption, and the maximum savings possible if the load shifting to off-peak times was applied. It also introduced a tariff that is more concerned in time of use rather than consumption only. The power consumption profile is collected for a sample house. The profile for a week was registered and graphed. The pricing suggested was calculated per day. Moreover, some samples applied worldwide were discussed to find a suitable model. It was found that a saving rate of $16 \%$ is achievable if the time of use charge is applied. Additionally, a peak load reduction of $3.5 \mathrm{kWH}$ average per day (in the peak hours) is possible.
\end{abstract}

Keywords: load management, smart grid, peak load, electricity tariffs and load profile.

\section{INTRODUCTION}

Peak Load is considered a critical measure, as it is an indicator for the amount of electricity significantly higher than the average level that is sustained for a short time. According to NEPCO's (National Electric Power company) annual reports for the years (2013 to 2015) the peak load is fluctuating as shown in Table 1. NEPCO's report for the year 2016 is detailed in Table 2.

The peak load reached $3165 \mathrm{MW}$ in summer and $3160 \mathrm{MW}$ in winter with a growth rate of $2.8 \%$ (winter). This increases the need to reduce the peak demand and produce smooth load profiles that can be predicted in order to minimize the need for peak time generators.

The energy problem in Jordan lies in the fuel availability and price, as most of the fuel used for electricity generation, i.e. natural gas and oil, is imported. The domestic resources are basically natural; solar, wind and biomass.

The need for smart grid is emerging mainly to balance the demand and production reducing the peak loads and integrate more renewables.
The term "Demand Side management" has been a topic for research for a lot of papers and theses related to the Smart Grid research. Studies have also suggested different ways and strategies of managing the home load in terms of energy cost. Each strategy has been evaluated using modelling and simulation. Other studies were dedicated to control, communication and devices modelling in order to determine the important parameters that affect the device behavior, customer comfort and needs as well as pricing of energy.

Roscoe and Ault [2010] produced residential load profiles by disaggregation of the demand seen at the transmission level. However, this approach will not capture the real-time changes of demand at a residential house (e.g. from minute to minute). However, in Jordan such surveys are not applied. Diekerhof et al. [2016] produced a scheduling algorithm that is dedicated for thermal loads only. In the case, the authors presented modelling for HVAC system only [Parvathy et al. 2016]. This is important to note, as these kinds of loads are the best candidates for scheduling and shifting. 
Table 1. Peak loads for Jordan-NEPCO reports

\begin{tabular}{|c|c|c|c|}
\hline Year & 2013 & 2014 & 2015 \\
\hline Peak (MW) & 2995 & 2930 & 3300 \\
\hline
\end{tabular}

Table 2. Peak loads for 2016 and 2015

\begin{tabular}{|l|c|c|}
\hline \multicolumn{1}{|c|}{ Year } & 2015 & 2016 \\
\hline Peak load summer (MW) & 3300 & 3165 \\
\hline Peak load winter (MW) & 3160 & 3250 \\
\hline Rate (\%) & -4.1 & 2.8 \\
\hline
\end{tabular}

The tariffs are also an important issue when managing house loads. The studies insisted on dynamic pricing of electricity as mentioned in the work of [Bahrami et al. 2012]; however, the dynamic pricing applicability is still an issue in Jordan. The simple incentives that take the form of high tariffs at times of extra ordinary high demand (critical peak pricing) presented by [Naus et al. 2014] are a good model to consider.

The shift to smart grid is important to satisfy the real power demand and match the supply with demand. Moreover, selling electricity from different supplier creating a trade commodity is also described in [Ferdous J. et al. 2017]. However, dynamic pricing needs a high level of forecasting to predict the load for the next day and adjust the pricing accordingly. It also has some risk in prediction [Gao et al. 2017].

The contribution of this study is to give a model based on Jordan and suggest a tariff that helps in reducing the peak loads and enhance consumers' savings.

\section{DEMAND SIDE MANAGEMENT STRATEGIES}

The demand side management is an approach taken by a lot of countries to minimize the peak demand. It is either mandatory by the utility supervisor (electricity distributor) or left to the customer choice, which is encouraged by incentives. The following examples detail the idea of such programs and their benefits for both the customer and supplier.

\section{Samples of Load Management Programs}

France has a network based demand side management system; the system has many features, the following are only two of them [https://particulier.edf.fr]
- Tempo Tariff - French Critical Peak Pricing Program - Always day-ahead alert for up to 22 days where energy is eight times more expensive. This is implemented through a device installed in houses and depends highly on communication.

- Automatic Circuit Breakers - When more power is used than subscribed for, then the automatic circuit breaker is triggered. There is no way for the consumer to override it, so the only thing to do is to switch off or unplug appliances and then try again.

The system has affected the nation to shift their behavior toward a situation that satisfies consumers and reduces the electricity costs. Implementing such programs in Jordan needs a communicationbased network that links the supplier and customer as well as a high level of forecasting and adequate pricing. Norway also has a very well-established system for tariffs. The government conducts studies and surveys to satisfy customers. It applies the time of use tariff with two peak periods that change according to the season. Demand side response is a question of mobilizing potential flexibility in how and when end users choose to use energy, and how such flexibility can provide value to the network [Copenhagen, 2017].

\section{JORDAN ELECTRICITY TARIFF}

\section{Peak demand}

The peak periods are the periods where the supplier is requested to deliver electricity in greater than average amounts, and maintain it for short period of time (15 or 30 minutes) The peak periods are announced for the industrial, agricultural and hotel sectors and adjusted continuously. Any facility that consumes energy in the peak period should pay a penalty of $2.65 \mathrm{JD} / \mathrm{kW}$ (Large Industrial Consumers) and $3.75 \mathrm{JD} / \mathrm{kW}$ for the other sectors mentioned earlier.

The problem of peak periods that they need special generation plants utility to match the needed load at the needed time. These plants have short starting times and the cost of generation is higher than other plants (with long ramping time). These periods set by the Energy and Mineral Regulatory Commission (EMRC) [http://emrc.gov.jo]. These periods are changed seasonally. In this study, the winter peak was taken into consideration; from 17 p.m. to 20 p.m. (winter timing). 


\section{Domestic tarif}

The domestic tariff in Jordan is presented in Table 3. The domestic tariff increases with consumption level and does not have peak limits.

\section{CASE STUDY}

\section{House model}

The first step is to specify the load and classification of appliances based on the control level [Mortaji et al. 2017]. The domain of this study covers the shiftable devices.

In order to gain information on the house load, a load program was collected on the course of one week (17/12-23/12-2017). There are 6 residents, with 2 employed parents. The following figures show the demand trend for the week days (Tuesday, Wednesday and Friday).

According to Figure 1, the power for the static devices is $490 \mathrm{~W}$. This is the allowable limit in the peak period. The pattern is noticed for week days and the difference is clear in the weekend. The continuous pattern shows the importance of

Table 3. Electricity price- NEPCO electricity tariff

\begin{tabular}{|c|c|}
\hline Consumption level, kWh & Price, fills/kWh \\
\hline $1-160$ & 33 \\
\hline $161-300$ & 72 \\
\hline $301-500$ & 86 \\
\hline $501-600$ & 114 \\
\hline $601-750$ & 158 \\
\hline $750-1000$ & 188 \\
\hline More than 1000 & 265 \\
\hline
\end{tabular}

peak avoidance, since it is a continuous behavior can be avoided by demand side management. It is also important to take care of the customer needs and comfort [Roy et al. 2017].

Assumptions:

- The suggested tariff is as follows:

$\mathrm{C}(\mathrm{t})=0.07,20<\mathrm{t}<17$, the third level.

$$
0.1, \quad 20>t>17
$$

Since the proposed house is on the third level of the electricity tariff and the peak period is the time between $5 \mathrm{pm}$ and $8 \mathrm{pm}$.

- The heater is considered to work on its average rate (full rate, for two hours) to simulate the temperature change which was hard to measure.

The tabulated consumption and savings are in the Results.

\section{RESULTS}

A simple spread sheet was prepared to calculate the saving earned for the customer to shift the controllable loads during the peak periods. The

Table 4. Devices power

\begin{tabular}{|l|c|c|}
\hline \multicolumn{1}{|c|}{ ApplianceS } & Power rate watt & Control degree \\
\hline Washing machine & 500 & shift-able \\
\hline Refrigerator & 150 & dimmable \\
\hline Lights & $100 \cdot 3$ & static \\
\hline TV & 40 & static \\
\hline Electric water heater & 2000 & shift-able \\
\hline
\end{tabular}

Static: can only be shut down in emergency.

Dimmable: Cannot change time of use but can be adjusted to reduce consumption.

Shift-able: can change the time of use.

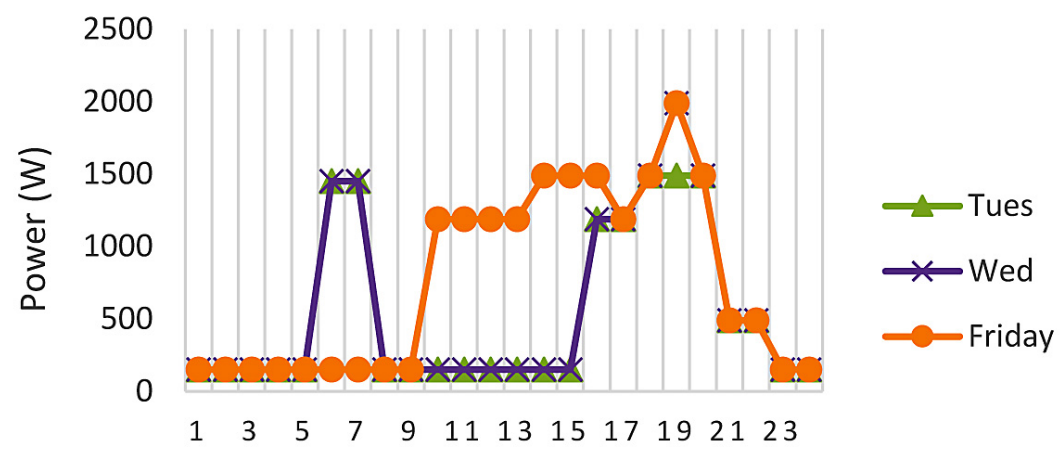

Time-hour of the day

Figure 1. Load profile 
Table 5. House consumption and cost without load management

\begin{tabular}{|l|c|c|c|}
\hline \multicolumn{1}{|c|}{ Day } & Total $(\mathrm{kWh})$ & $\begin{array}{c}\text { Peak load } \\
\text { without } \\
\text { sifting }\end{array}$ & Cost, JD/day \\
\hline Sunday & 12.98 & 4.47 & 1.12 \\
\hline Monday & 12.83 & 4.47 & 1.10 \\
\hline Tuesday & 12.83 & 4.47 & 1.10 \\
\hline Wednesday & 13.33 & 4.97 & 1.15 \\
\hline Thursday & 12.83 & 4.47 & 1.10 \\
\hline Saturday & 17.87 & 4.97 & 1.54 \\
\hline Friday & 17.37 & 4.47 & 1.49 \\
\hline
\end{tabular}

Table 6. House consumption and cost with load management

\begin{tabular}{|l|c|c|c|c|c|}
\hline \multicolumn{1}{|c|}{ Day } & $\begin{array}{c}\text { Total } \\
(\mathrm{kWh})\end{array}$ & $\begin{array}{c}\text { Peak } \\
\text { load } \\
(\mathrm{kwh})\end{array}$ & $\begin{array}{c}\text { Peak } \\
\text { cost, } \\
\text { JD }\end{array}$ & $\begin{array}{c}\text { Total } \\
\text { cost, } \\
\text { JD/day }\end{array}$ & $\begin{array}{c}\text { Saving, } \\
\%\end{array}$ \\
\hline Sunday & 12.98 & 1.47 & 0.147 & 0.95 & 14.65 \\
\hline Monday & 12.83 & 1.47 & 0.147 & 0.94 & 14.61 \\
\hline Tuesday & 12.83 & 1.47 & 0.147 & 0.94 & 14.61 \\
\hline Wednesday & 13.33 & 1.47 & 0.147 & 0.98 & 14.76 \\
\hline Thursday & 12.83 & 1.47 & 0.147 & 0.94 & 14.61 \\
\hline Saturday & 17.87 & 1.47 & 0.147 & 1.30 & 15.74 \\
\hline Friday & 17.37 & 1.47 & 0.147 & 1.26 & 15.65 \\
\hline
\end{tabular}

cost saving per day was calculated and shows in table 5 and 6 .

The assumption is that at the peak time, only critical loads are allowed to operate, and the consumption is distributed over the off-peak period.

\section{CONCLUSIONS}

The demand side management helps in determining when to use the electricity in a way that satisfies the customers need (to some limits) and reduce the electricity generation costs. This is reflected as incentives to customers. The incentive-based systems are the most attractive systems that assure involvement of customers. In order to apply the demand side management, there should be a system of planning, forecasting and communication.

The proposed example clarifies the importance of pricing in peak reduction. However, it is clear that this is not possible without smart metering, producing both time of use schedules as well as consumption. When dealing with home appliances it is important to control heating appliances and shift able appliances where as other appliances like TVs, lights, computers etc. shall not be controlled to maintain the customers comfort. It is important to note that with the increase in electric vehicles use in Jordan, demand management will be an issue to consider, as electric vehicles represent an added load to domestic sector.

\section{REFERENCES}

1. Bahrami Sh., Parniani M. and Vafaeimehr V. 2012. A modified approach for residential load scheduling using smart meters. Innovative Smart Grid Technologies (ISGT Europe). Berlin, Germany, 14-17 Oct. 2012.

2. Demand side flexibility in the Nordic electricity market: From a distribution system operator perspective. Copenhagen, 2017.

3. Diekerhof M., Schwarz S., Monti A. 2016. Distributed optimization for electro-thermal heating units. IEEE PES Innovative Smart Grid Technologies Conference Europe (ISGT-Europe), Ljubljana, Slovenia, 1-6.

4. Ferdous J. et al. 2017. Optimal dynamic pricing for trading-off user utility and operator profit in smart grid. In: IEEE Transactions on Systems, Man, and Cybernetics: Systems, 1-13. DOI: 10.1109/ TSMC.2017.2764442.

5. Gao G., Lo K. and Lu J., 2017. Risk assessment due to electricity price forecast uncertainty in UK electricity market. In: 52nd International Universities Power Engineering Conference (UPEC), Heraklion, Crete, Greece, 2017, pp. 1-6.

6. http://emrc.gov.jo/images/electric/electmax 2017. pdf. 27/12/2017

7. https://particulier.edf.fr/en/home/energy-at-home/ electricity/blue-tariff.html. 27/12/2017

8. Mortaji H., Hock Ow S., M. Moghavvemi, Almurib H.A.F. 2017. Load shedding and smart-direct load control using internet of things in smart grid demand response management. IEEE Transactions on Industry Applications, 53(6), 5155-5163.

9. Naus J., Spaargaren G., Van Vliet B.J.M., Van der Horst H.M. 2014. Smart grids, information flows and emerging domestic energy practices. Energy Policy, 68, 436-446.

10. Parvathy S., Patne N.R., Jadhav A.M., 2016. A smart demand side management mechanism for 
domestic energy consumers with major HVAC load. International Conference on Electrical Power and Energy Systems, Bhopal, India, 504-511. DOI: 10.1109/ICEPES.2016.7915982.

11. Roscoe J. and Ault G. 2010. Supporting high penetrations of renewable generation via implementation of real-time electricity pricing and demand response.
IET Renewable Power Generation, 4, 369-382.

12. Roy T., Das A. and Ni. Z. 2017. Optimization in load scheduling of a residential community using dynamic pricing. In: IEEE Power \& Energy Society Innovative Smart Grid Technologies Conference (ISGT), Washington, DC: IEEE. DOI: 10.1109/ISGT.2017.8086087. 